\title{
Certificates of deposit - a key element of the Bacteriological Code and an indispensable prerequisite for comparative taxonomic research. Report of a case of falsification and a reply to the Letter to the Editor by Tindall (2008)
}

Taxonomy is basically a comparative science. Compared with other scientific disciplines, the verification of newly obtained data with already published data is of considerable importance. In order to fulfil this essential requirement, authentic biological material, in this case the type strains, plays a key role. Therefore the unrestricted availability of type strains is a crucial prerequisite for the performance of comparative research and for the production and verification of the scientific literature based on them. Traditionally the Codes of nomenclature have provided the theoretical background to ensure the principle of typification. For prokaryotic organisms, the International Code of Nomenclature of Bacteria (the Bacteriological Code) (Lapage et al., 1992; De Vos \& Trüper, 2000; De Vos et al., 2005; Tindall et al., 2008) has resulted in a well established and workable system where the availability of the appropriate viable and authentic type material is regulated. Individual culture collections play a key role in this system with the storage, maintenance and distribution of the type material for comparative taxonomic studies.

In this regard, it is essential that an impartial dialogue exists between the culture collections holding the type strains, the committees responsible for the content of the Bacteriological Code (the ICSP and the Judicial Commission of the ICSP), the Editors of the International Journal of Systematic and Evolutionary Microbiology (IJSEM; as the official organ of the ICSP) and of course the scientists involved in systematic research to ensure that this mutually beneficial system is kept stable and reliable.

This framework has led to the development of a widely available, accessible and reliable up-to date reference system which includes all validly published taxonomic names (and their synonyms), their scientific descriptions and the location of the appropriate type material for the vast majority of names in use according to the Bacteriological Code (see http://www.bacterio.cict.fr) and facilitates further systematic research.

For this reason (starting from January 2001; De Vos \& Trüper, 2000; Labeda, 2000), authors of novel species, novel subspecies and new combinations have to provide evidence that type strains are deposited in at least two recognized culture collections in two different countries. Since August 2002, the IJSEM, as the official organ of the ICSP, has asked that authors provide documented evidence from the culture collections confirming the deposition and availability of their type strains.

In the majority of cases, this documentary evidence is fulfilled on the basis of 'Certificates of Deposit'.

In 2005, the Judicial Commission of the ICSP and the ICSP decided unanimously (Tindall et al., 2008, Labeda \& Oren, 2008) to change the wording of Rule 30 to the following:

'As of 1 January 2001 the description of a new species, or new combinations previously represented by viable cultures must include the designation of a type strain, and a viable culture of that strain must be deposited in at least two publicly accessible service collections in different countries from which subcultures must be available. The designations allotted to the strain by the culture collections should be quoted in the published description. Evidence must be presented that the cultures are pre- sent, viable and available at the time of publication'.

In this regard, a case of falsification of 'Certificates of Deposit' has become apparent to the Editorial Office. In brief, I was contacted by a culture collection curator because of concerns about three type strains that had been deposited in their collection by the same group of researchers. Investigation by Editorial Office staff suggested that the certificates that had been provided by the authors (which took the form of unprotected Word files) might not have been issued by the culture collection concerned. The Editorial Office staff then undertook an investigation of the certificates from this collection provided in conjunction with all papers submitted by this group and asked the collection to confirm: (i) which specific curator was responsible for handling that strain, (ii) whether they had issued a certificate for that strain, and (iii), if so, the date on which the certificate was issued. This investigation suggested that a total of six certificates provided by this group had not been issued by the culture collection. All six were apparently signed by the same curator (who had not in fact been responsible for handling three of the strains, hence the original suspicion).

The IJSEM is a member of COPE (Committee on Publication Ethics). Following the COPE guidelines for suspicions of fabricated data as the closest match to this situation, I contacted the corresponding author of these papers and asked for an explanation. The corresponding author was extremely apologetic and indicated that one of his coauthors had been responsible for obtaining certificates for these strains but that this coauthor had since left his laboratory and returned to his native country. I contacted this co-author and he admitted that he had produced the forged certificates in an 
attempt to expedite publication, and thereby secure priority for the names, without the knowledge of the corresponding author or his other co-authors.

Because evidence has therefore not been provided that these type strains have been deposited in two culture collections in two different countries, the descriptions do not fulfil the requirements of the Bacteriological Code and I, in my role as Editor, took the following decisions: (i) a single paper that had been published in print was retracted, and (ii) four papers that had been published ahead of print but not in print were retracted in print, as these papers had already been listed by PubMed. A sixth paper that was still under review was withdrawn by the corresponding author at the suggestion of the Editor in Chief.

A retraction statement was drawn up after consulting the recently published COPE guidelines on retractions and the wording was agreed by the corresponding author and the co-author responsible for the forged certificates. The statement indicated that a certificate was provided by the named responsible author, without the knowledge of his co-authors, that had not been issued by the culture collection concerned. These retractions were published in the January 2010 issue of IJSEM (Volume 60, Part 1).

In addition, I have brought this case to the attention of the institution where the person responsible is working and have asked for an investigation of this case of deliberate misconduct and that any recommended action should be taken as governed by the ethics committee of this institution.

This example highlights again the importance of these documents and I would like to draw the attention of the curators of all the culture collections to this problem and ask them to take all necessary steps to prevent their certificates from being similarly manipulated. The main advice from COPE was to make it clear in future that the authenticity of the certificates is something for which all authors should take responsibility. I would like to take this opportunity to remind all authors of the principle of joint responsibility.

It is not only the formal authenticity of these documents that is important. At this point, I would like to revisit some problems that have been addressed by Tindall (2008) in a Letter to the Editor. He pointed out correctly that the terms 'Certificate of Deposit', and 'confirmation of deposit' are sometimes not used in the same sense.

However, regardless of a possible different interpretation of these terms, the key element as laid down in Rule 30(b) is that the deposit of type strains is confirmed and the most important point is that the collection in question is clearly identified as the source.

Tindall (2008) proposed the following requirements, which must be fulfilled in order to conform to the current Rules of the Code:

'...(i) the 'confirmation of deposit' applies to the deposit of all type strains of new species and subspecies, as well as new combinations, where it is otherwise impossible to determine that the strain in question has been allocated a particular collection number;

(ii) the collection can confirm that the strain deposited represents the type strain of the taxon in question. Depositors of strains are responsible for making available to the collections all information on the properties of the strain that may be required to fulfil that task;

(iii) that the strain is viable, which would include confirmation of the fact the strain has been successfully stored by appropriate methods (freeze drying, liquid drying, freezing, etc.);

(iv) that the strain will be available at the time the publication appears and that the collection number does not apply to a number issued solely for patent purposes or a safe deposit or that other forms of restrictions that would hinder bona fide systematic research have not been imposed;

(v) documentation provided by the collections should clearly identify the collection as the source of that information. The listing of names and collection numbers on delivery slips or invoices is not adequate;

(vi) in order for names to be validly published, the appropriate type strains designated in the manuscript in the IJSEM or published in papers in another journal submitted for inclusion in the Validation Lists must be accompanied by documentation that allows the editors and the ICSP to confirm that the five conditions listed above have been met by two different collections in two different countries. Strain numbers from additional collections that are unable to comply with all these points may also be included, but would not be considered to fulfil the requirements of the Code.'

In essence, these requirements should help authors, editors, reviewers and culture collections to conform to the current rules of the Code. The vast majority of the Editorial Board members of the IJSEM support these helpful suggestions and it is assumed that these requirements are essentially fulfilled when documented evidence is provided, i.e. a 'Certificate of Deposit' is issued by a culture collection and submitted along with a manuscript to the Editorial Office.

Of course, the Editors of IJSEM can not control the authenticity of these documents. It is also far beyond the control of the Editorial Board to check whether all requirements (i) to (vi) have been fulfilled.

As stressed by Tindall (2008), it is essential to reiterate that it remains the sole responsibility of the depositor(s) to supply the culture collections with the type strains well in advance of publication so that they can complete their work. It remains the sole responsibility of the depositor(s) to ensure that authentic type material is sent to the collections (Tindall, 2008). One would expect that these requirements addressed to the authors of taxonomic papers are self-evident. Nevertheless, Tindall (2008) pointed out correctly that the requirements listed above centre on the work of the collections. In many cases, collections are not only verifying the type material held in their collections at the time of accession but are also verifying other data associated with the type 
material, thus helping to minimize errors in the published literature, which is very much appreciated.

In principle, the requirements addressed by Tindall (2008) will help to ensure that higher standards are being applied to taxonomic work, enabling the key elements of verifying existing experimental data and expanding on the dataset associated with authentic biological material (type strains) to be carried out. In this regard, I would also support the 'Proposals to clarify how type strains are deposited and made available to the scientific community for the purpose of systematic research' by Tindall \& Garrity (2008). A clarification on how type strains are to be deposited would benefit all involved parties, the collections and the end-users.

As proposed by Tindall \& Garrity (2008), this issue should be discussed by the ICSP, by the collections themselves and also within culture collection organizations such as the WFCC, ECCO, UKFCC, JFCC and USFCC, and by federations of societies such as IUMS and FEMS and individual national societies.

It is vital for the persistence of the abovementioned mutually beneficial system that a workable conclusion of this issue is resolved as soon as possible by the introduction of clear requirements and/or quality standards approved by the ICSP.

\section{Peter Kämpfer}

Institut für Angewandte Microbiologie, Justus-Liebig-Universität Giessen, Heinrich-Buff-Ring 26-32 (IFZ), D-35392, Giessen, Germany

Correspondence: Peter Kämpfer (peter.kaempfer@agrar.uni-giessen.de)

De Vos, P. \& Trüper, H. G. (2000). Judicial Commission of the International Committee on Systematic Bacteriology. IXth International (IUMS) Congress of Bacteriology and Applied Microbiology. Minutes of the meetings, 14, 15 and 18 August 1999, Sydney, Australia. Int J Syst Evol Microbiol 50, 2239-2244.

De Vos, P., Trüper, H. G. \& Tindall, B. J. (2005). Judicial Commission of the International Committee on Systematics of Prokaryotes. Xth International (IUMS) Congress of Bacteriology and Applied Microbiology. Minutes of the meetings, 28, 29 and 31 July and 1 August 2002, Paris, France. Int J Syst Evol Microbiol 55, 525532.

Labeda, D. P. (2000). International Committee on Systematic Bacteriology. IXth International
(IUMS) Congress of Bacteriology and Applied Microbiology. Minutes of the meetings, 14 and 17 August 1999, Sydney, Australia. Int J Syst Evol Microbiol 50, 2245-2247.

Labeda, D. P. \& Oren, A. (2008). International Committee on Systematics of Prokaryotes. XIth International (IUMS) Congress of Bacteriology and Applied Microbiology. Minutes of the meetings, 23, 24, 26 and 28 July 2005, San Francisco, CA, USA. Int J Syst Evol Microbiol 58, 1746-1752.

Lapage, S. P., Sneath, P. H. A., Lessel, E. F., Skerman, V. B. D., Seeliger, H. P. R. \& Clark, W. A. (editors) (1992). International Code of Nomenclature of Bacteria (1990 Revision). Bacteriological Code. Washington, DC: American Society for Microbiology.

Tindall, B. J. (2008). Confirmation of deposit, but confirmation of what? Int J Syst Evol Microbiol 58, 1785-1787.

Tindall, B. J. \& Garrity, G. M. (2008). Proposals to clarify how type strains are deposited and made available to the scientific community for the purpose of systematic research. Int J Syst Evol Microbiol 58, 1987-1990.

Tindall, B. J., De Vos, P. \& Trüper, H. G. (2008). Judicial Commission of the International Committee on Systematics of Prokaryotes. XIth International (IUMS) Congress of Bacteriology and Applied Microbiology. Minutes of the meetings, 23, 24 and 27 July 2005, San Francisco, CA, USA. Int J Syst Evol Microbiol 58, 1737-1745. 